\title{
Degradation of Japanese Lacquer under Wavelength Sensitivity of Light Radiation
}

\author{
Kosuke Nakagoshi, Kunio Yoshizumi* \\ Kyoritsu Women's University, Tokyo, Japan. \\ Email: "yoshizumi@kyoritsu-wu.ac.jp \\ Received June 24 $4^{\text {th }}, 2011$; revised July $24^{\text {th }}, 2011$; accepted August $8^{\text {th }}, 2011$.
}

\begin{abstract}
Degradation of Japanese lacquer caused by light irradiation was examined at various wavelengths. By exposing lacquer specimens to a narrow monochromatic light band isolated from dispersed polychromatic light emitted by a Xe lamp source, the wavelength sensitivity characteristics of lacquer degradation could be determined on the basis of radiant energy. Tame-Urushi (brown) lacquer displayed peak degradation maxima at 220 and $315 \mathrm{~nm}$. A broad shoulder peak was also observed in UVA. For Shu-Urushi (cinnabar) lacquer, in addition to peaks in the UVA-UVB range, a large degree of degradation was observed following exposure to light in the visible range. Ao-Urushi (green) lacquer showed similar characteristics, although it was less prone to degradation. Similarly, Shin-Urushi (black) lacquer showed little change in response to light, although UV light caused limited degradation. These results indicate that along with the damage caused by UVA and UVB, visible light in the range $510-650 \mathrm{~nm}$ may also have a significant degradation effect. Our results provide experimental evidence that Japanese lacquer responds differently to light of various wavelengths and that specific wavelengths, including visible light, can cause significant degradation.
\end{abstract}

Keywords: Japanese Lacquer, Degradation, Wavelength Sensitivity, Monochromatic Light, Spectral Reflectance, Visible Light

\section{Introduction}

Japanese lacquer, Urushi, is a natural polymer, which is used to decorate many types of crafts [1]. Raw lacquer is an oil-in-water emulsion that is traditionally collected as sap from specific Urushi trees [2]. Unlike synthetic paints that dry by solvent evaporation, Urushi dries by polymerization in moist air. As a result, the molecules join together and form a hard, lustrous, and durable coating [1-3].

Despite the legendary stability provided by its nonrepeating polymeric cross-linked structure, the lacquer surface is susceptible to damage by light and color photobleaching [1,3]. Moreover, this damage by light is not reversible. Therefore, restoration of Urushi crafts damaged by light is of great concern [4].

The chemical pathways by which synthetic polymers undergo photodegradation have been fairly well investigated [5-10]. UV radiation triggers many concurrent chemical processes in polymers exposed to it and results in various modes of damage [11]. Moreover, polymer stability has been investigated widely to examine the properties [12-16]. However, research on Urushi lacquer degradation has been minimal, possibly because of limited information about the process [3].

Assessing the damage caused to materials because of light exposure requires an understanding of their spectral sensitivity. Spectral sensitivity data for polymers are typically generated using a source of monochromatic radiation or a filtered Xe white light source $[6,7,11,17]$. In the field of biology, results on wavelength sensitivity have been published [18-20].

In this study, we focused on the wavelength sensitivity of Japanese lacquer to degradation. Wavelength of light irradiation is one of the most important factors in the degradation process $[6-9,17]$. Ultraviolet radiation is known to strongly promote degradation of materials [11]. In addition, visible light is considered to contribute to lacquer degradation in some cases [21]. However, few studies have focused on the dependency of degradation of materials on the wavelength of irradiation. For instance, dyestuffs are strongly influenced by light irradiation [22-32]; however, there is little information on whether specific wavelengths of light are more damaging 
than others.

In the present study, the degradation characteristics of Japanese lacquer containing pigmented color sources were investigated by performing a wavelength sensitivity analysis on a radiant energy basis. The lacquer samples were first exposed to monochromatic light, and the wavelength dependency of degradation was determined on the basis of action spectra. The results are expected to provide crucial information about the conservation of traditional Japanese lacquer crafts in museums and art galleries as well as an increased understanding of natural polymer sciences.

\section{Experimental}

\subsection{Materials}

The lacquer material obtained from the sap of Urushi trees was traditionally used to coat wood substrates. The primary component of lacquer is Urushiol, the chemical structure of which is shown in Figure 1. Raw lacquer comprises the following major components: $60 \%-65 \%$ Urushiol (pyrocatechol derivatives), 20\% - 25\% water, $8 \%$ carbohydrates, and $2 \%$ glycoproteins. Lacca, one of the glycoproteins, acts as a catalyst in the presence of oxygen and moisture to cause polymerization of the Urushiol molecules. For colorization, pigments were added to the primitive lacquer. Four different colors were examined in this study, prepared by adding cinnabar, copper oxide, and iron oxide to about $1 \%$ of primitive lacquer on a weight basis. The first sample, called TameUrushi, is natural dark lustrous brown without any added pigment. The second one, called Shu-Urushi, is prepared by adding cinnabar and mercuric sulfide. The third one, Ao-Urushi, is prepared by adding copper oxide and is green. The fourth one, Shin-Urushi, is prepared by adding iron oxide and is black.

\subsection{Exposure to Light Sources}

The samples were irradiated with monochromatic light by using a JASCO CRM-FD spectroirradiator (Figure 2).

The spectroirradiator was equipped with a $300 \mathrm{~W}$ Xe

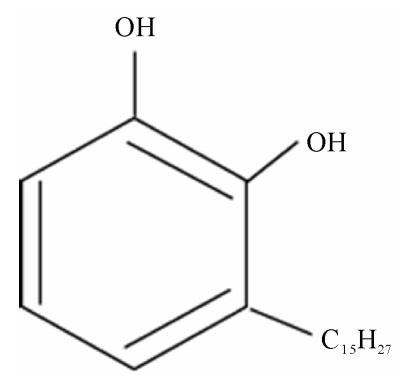

Figure 1. Chemical structure of Urushiol.

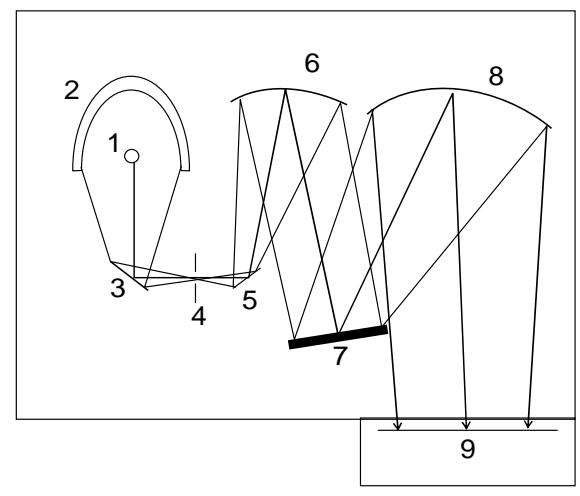

Figure 2. Schematic diagram of the spectro-irradiator: 1. Xenon arc lamp; 2. elliptical sphere mirror; 3. mirror; 4. slit; 5. mirror; 6. mirror; 7. diffraction grating; 8. mirror; 9. sample holder.

arc lamp with an elliptical half-sphere mirror to collect emitted light. Radiation from this source was converted into monochromatic light by using a diffraction lattice grate with 1200 lines $/ \mathrm{mm}$. The wavelength dispersion was about $2 \mathrm{~nm} \cdot \mathrm{mm}^{-1}$ and the slit was set to $2 \mathrm{~mm}$, resulting in an irradiation range of approximately $4 \mathrm{~nm}$ for each irradiation wavelength. The specimens were positioned in a sample holder and exposed to monochromatic radiations spaced at $16 \mathrm{~nm}$ intervals within the $208-650$ $\mathrm{nm}$ wavelength range. For each wavelength, the light intensity in $\mathrm{W} / \mathrm{m}^{2} / \mathrm{nm}$ was periodically measured using a photometer. The photometer consisted of a thermopile detector attached to the spectroirradiator. Light exposures were conducted at temperature and relative humidity ranging from $20^{\circ} \mathrm{C}$ to $25^{\circ} \mathrm{C}$ and from $50 \%$ to $70 \%$, respectively. These systems were also used in previous experiments published elsewhere [33-35].

\subsection{Evaluation of Fading}

Color change of the specimen was measured using a Minolta Model CM-3700d color analyzer with a $4 \times 7$ $\mathrm{mm}^{2}$ viewing aperture. The amount of fading was evaluated in terms of color difference and was calculated using the following formula proposed by the CIE Committee in 1976:

$$
\Delta \mathrm{E}=\left[(\Delta \mathrm{L} *)^{2}+\left(\Delta \mathrm{a}^{*}\right)^{2}+\left(\Delta \mathrm{b}^{*}\right)^{2}\right]^{1 / 2},
$$

where $\Delta \mathrm{L}^{*}$ is the lightness-darkness difference, $\Delta \mathrm{a}^{*}$ is the redness-greenness difference, and $\Delta b^{*}$ is the yellowness-blueness difference.

The reflectance spectra of the lacquer specimens were also measured by the above color analyzer.

\subsection{Determination of Radiant Wavelength Sensitivity}

The accumulated energy $\left(\mathrm{J} / \mathrm{m}^{2} / \mathrm{nm}\right)$ was calculated in light intensity $\left(\mathrm{W} / \mathrm{m}^{2} / \mathrm{nm}\right)$ by exposure time for each ex- 
posure wavelength, because the light source is not expected to radiate at the same intensity for each wavelength. For a specimen, the relationship between the accumulated radiant energy and the color difference was examined in a time series experiment at each exposure wavelength. Then, a smooth curve was drawn to model the representative fading rates. Measured color changes recorded at a specified radiant energy was then determined from the curve to obtain wavelength sensitivity of the lacquer at each wavelength.

\section{Results and Discussion}

\subsection{Color Features of Pigmented Japanese Lacquer}

Figure 3 shows the reflectance spectra of the lacquer specimens: (1) Tame-Urushi (brown); (2) Shu-Urushi (cinnabar); (3) Ao-Urushi (green); and (4) Shin-Urushi (black).

In Figure 3, panel (1), the reflectance begins to increase at wavelengths around $560 \mathrm{~nm}$ and continues to increase, although all reflectance levels are less than $10 \%$ within the visible light range. Such low reflectance implies a dark brown color.

In Figure 3, panel (2), the reflectance increases considerably from approximately $6 \%$ at a wavelength 590 $\mathrm{nm}$ to approximately $20 \%$ at $600 \mathrm{~nm}$. Further, it contin-
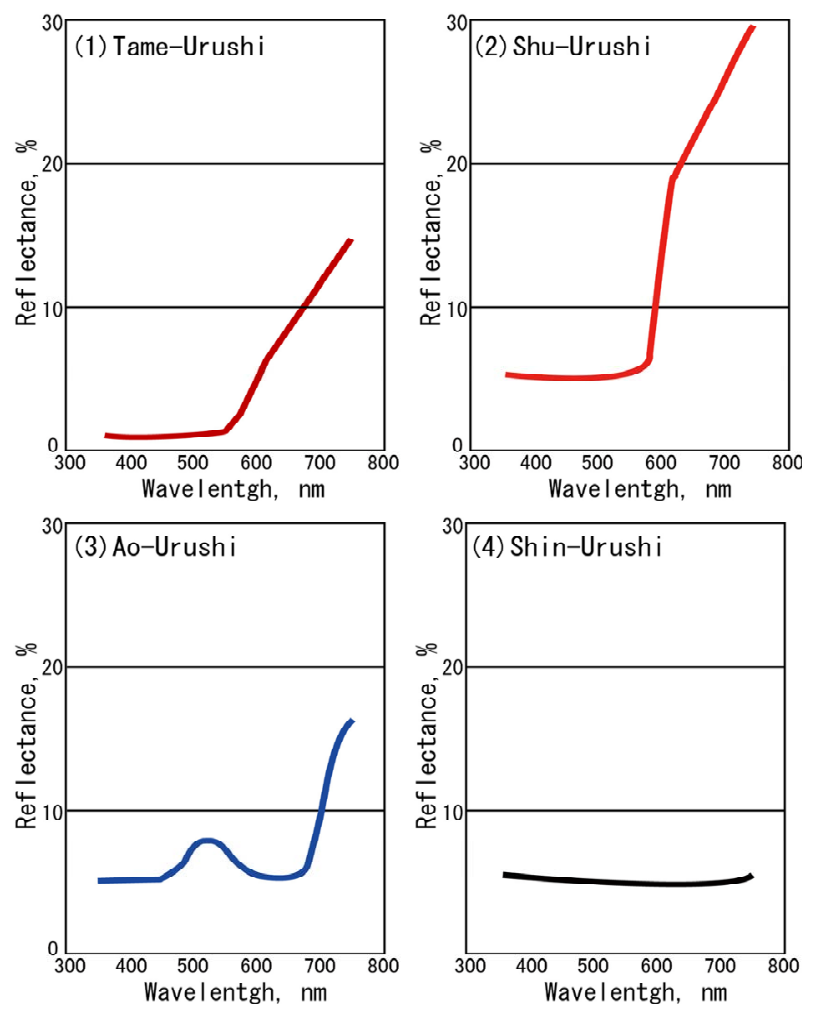

Figure 3. Reflectance spectra of (1) Tame-Urushi; (2) ShuUrusi; (3) Ao-Urushi; and (4) Shin-Urushi. ues to increase gradually to approximately $30 \%$ at a wavelength $700 \mathrm{~nm}$. These characteristics clearly indicate a bright red color.

In Figure 3, panel (3), the reflectance peaks at wavelengths within the range of $460-610 \mathrm{~nm}$, indicating a bluish-green color. However, the reflectance level is only $6 \%-8 \%$, signifying a dark tone.

Figure 3, panel (4) shows that the reflectance appears flat across the visible light range with low reflectance level at approximately $5 \%$. This is a specific characteristic of black.

\subsection{Fading Characteristics of Japanese Lacquer under Monochromatic Light}

As described in the experimental section, the degradation results shown in Figures 4-7 were obtained on specimens exposed to a narrow radiation band isolated from the dispersed polychromatic light. In this case, the strength of irradiance depends on the light wavelength because the source does not emit wavelengths of equal intensities. We can compensate for this by varying the exposure time at each wavelength in order to maintain a constant irradiance.

Figure 4 shows the fading characteristics of TameUrushi following exposure to monochromatic light irradiation at wavelengths 373,451 , and $613 \mathrm{~nm}$. These wavelengths were selected as representatives of the overall light exposures that cause fading. Each curve shows the variation in the specimen color under a continuous monochromatic radiation at a constant wavelength. Fading levels are increased with increasing accumulated radiant energy. Instead of a linear fading rate, the resulting fading rate was found to be curved. The color following irradiation at $373 \mathrm{~nm}$ is most considerably faded, representing a color difference of about 10 . The next most severe fading is seen following irradiation at $451 \mathrm{~nm}$. The least fading is observed under irradiation at $613 \mathrm{~nm}$, representing a color difference of about 2 .

Note that in addition to variation in color due to chemical changes of the material, fading measured here incorporates dull appearance that occurs as a result of very fine cracks on the surface of the lacquer following irradiation. In this study, overall light degradation at the specimen surface is evaluated by fading measured as difference in color.

These results imply that the energy contained in both ultraviolet and visible light is sufficient to break the molecular bonds of the Urushi polymer. At the same time, because ultraviolet light contains more energy, it is understandable that it causes more damage to lacquer.

Figure 5 shows the fading characteristics of ShuUrushi following irradiation with monochromatic light at 373,451 , and $613 \mathrm{~nm}$. Similar to the fading shown in 

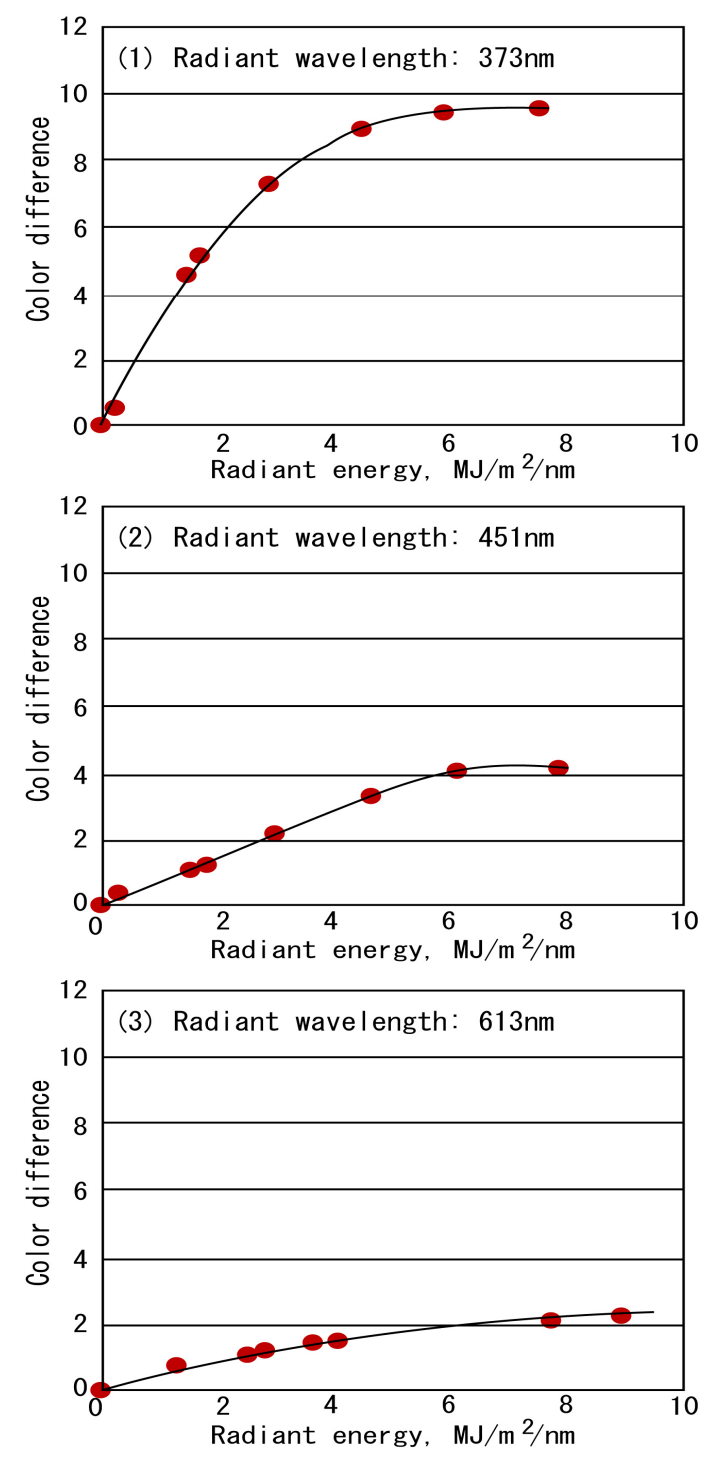

Figure 4. Fading character of Tame-Urushi under (1) 373; (2) 451; and (3) $613 \mathrm{~nm}$ of monochromatic light irradiation.

Figure 4, fading for Shu-Urushi lacquer was highest at $373 \mathrm{~nm}$, moderate at $451 \mathrm{~nm}$, and least at $613 \mathrm{~nm}$. However, the degradation following irradiation in the visible range was more remarkable than for Tame-Urushi.

Figure 6 shows the fading characteristics of AoUrushi following irradiation with monochromatic light at 373,451 , and $613 \mathrm{~nm}$. On the whole, the degradation features of Ao-Urushi were similar to those of ShuUrushi, although Ao-Urushi seems to be more resistant to fading in general and is more colorfast than Shu-Urushi.

Figure 7 shows the fading characteristics of ShinUrushi following monochromatic light irradiation at 373 , 451 , and $613 \mathrm{~nm}$. The fading is lower compared to that of other lacquers discussed in this study. Shin-Urushi seems to be quite colorfast and resistant to light degradation.
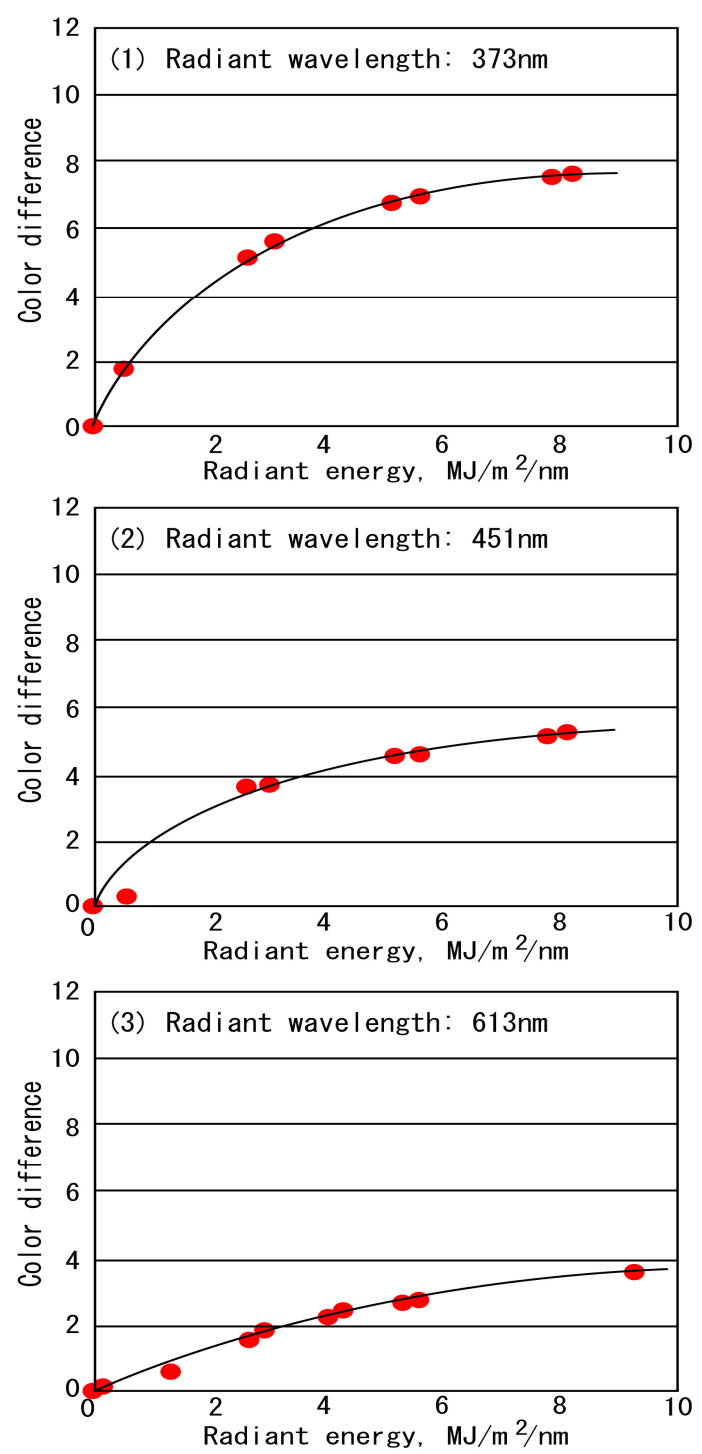

Figure 5. Fading character of Syu-Urushi under (1) 373; (2) 451; and (3) $613 \mathrm{~nm}$ of monochromatic light irradiation.

However, even at a low level, the fading level is most remarkable at $373 \mathrm{~nm}$, which suggests that ultraviolet light exposure induces more lacquer degradation. In this study, degradation of lacquer was methodically evaluated, characterizing changes in color in terms of reflectance at the material surface. In fact, some degradation products may be manifest as small molecules that might be easily lost at the surface of the material. These molecules have not been previously reported [1,3]. Moreover, water plays an important role in lacquer degradation. Water, beginning as one of the main components of the sap, contributes to polymerization of lacquer. Up to $3 \%$ of the water is considered to remain bound in the final lacquer coating, even after drying, as part of hydrophilic compounds [1]. This water loss may lead to internal stress 

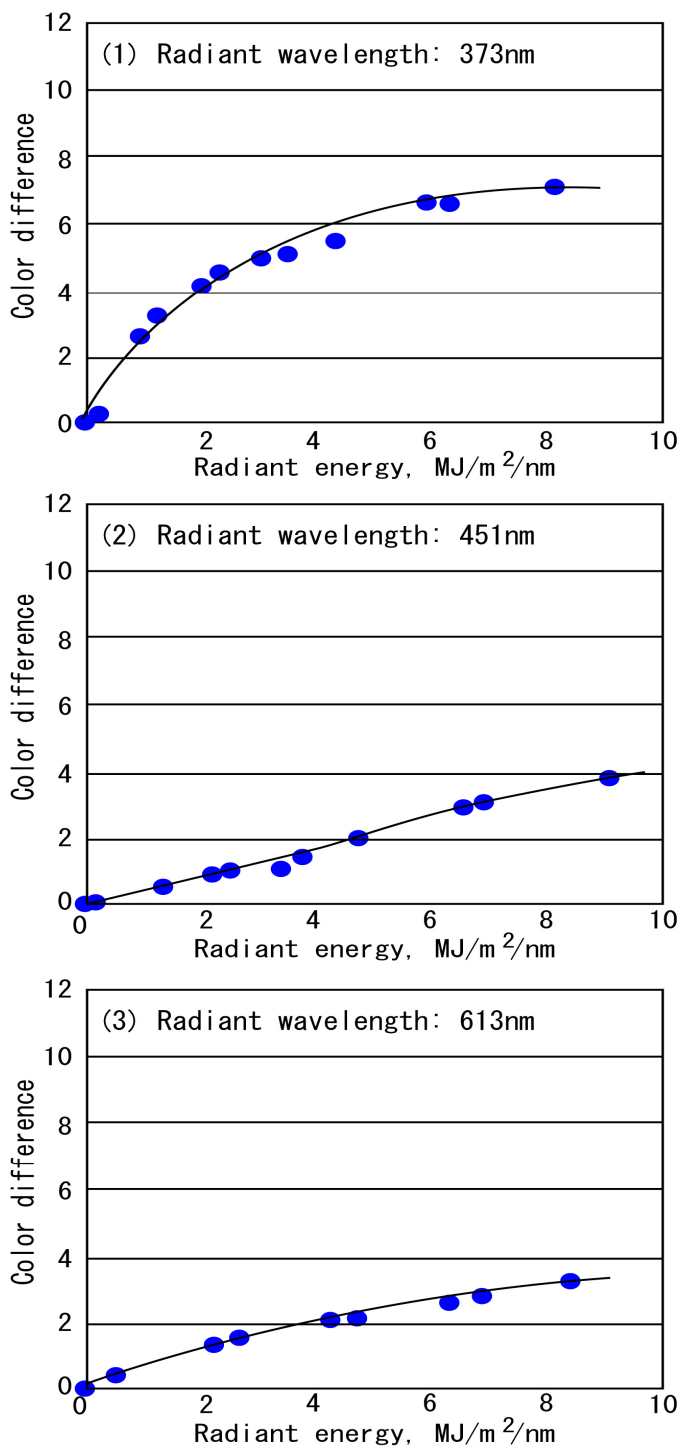

Figure 6. Fading character of Ao-Urushi under (1) 373; (2) 451; and (3) $613 \mathrm{~nm}$ of monochromatic light irradiation.

and possible cracking, causing degradation of lacquer.

\subsection{Wavelength Sensitivity}

The wavelength sensitivity characteristic, also known as an action spectrum $[13,28,36]$, for the degradation of Tame-Urushi is shown in Figure 8. In this study, the fading characteristics of the lacquer coated specimens were determined when the accumulated radiant energy reached $5 \mathrm{MJ} / \mathrm{m}^{2} / \mathrm{nm}$ for each wavelength, as shown in Figures 4-7.

In Figure 8, two intense peaks were observed at 220 and $315 \mathrm{~nm}$ in the UVB-UVC range for Tame-Urushi. Moreover, a large and broad shoulder peak was observed. This suggests that UVA radiation has a significant degradation effect, whereas visible light causes lesser degree
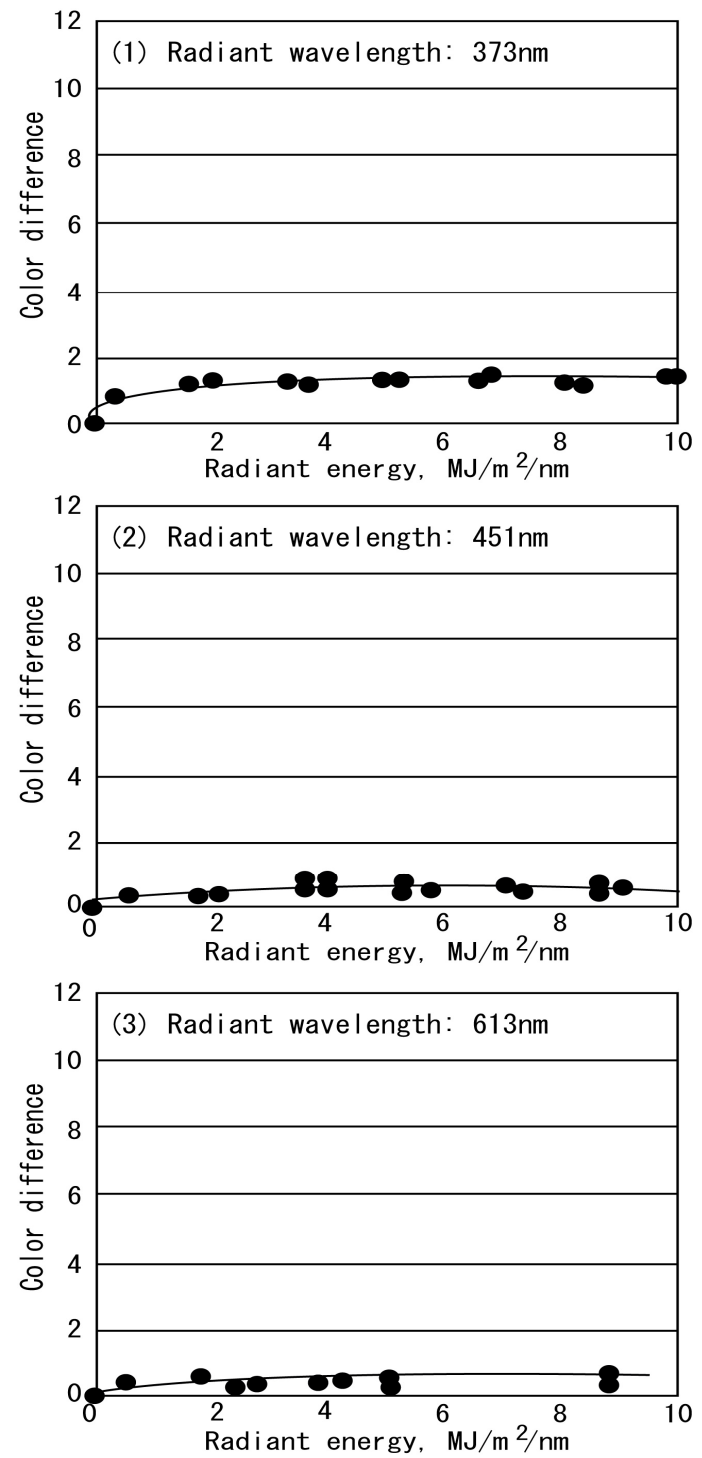

Figure 7. Fading character of Shin-Urushi under (1) 373; (2) 451; and (3) $613 \mathrm{~nm}$ of monochromatic light irradiation.

of degradation.

Figure 9 shows the wavelength sensitivity characteristics for the degradation of Shu-Urushi under a radiant energy of $5 \mathrm{MJ} / \mathrm{m}^{2} / \mathrm{nm}$ at each wavelength. A large peak is shown at $220 \mathrm{~nm}$ in UVC. In addition, a combined large and broad peak is observed in the UVA-UVB range. This indicates that the lacquer is strongly degraded under UVA sunlight irradiation. Moreover, for Shu-Urushi, the degradation peak is observed in the green-red light range of $510-650 \mathrm{~nm}$. Because the intensity of sunlight is maximal around this wavelength, it is expected that Shu-Urushi would be especially prone to degradation by accumulating sunlight intensity during daily usage. This agrees with a previous report by Umney, which suggests that the lift time for red lacquer is eight months and three 


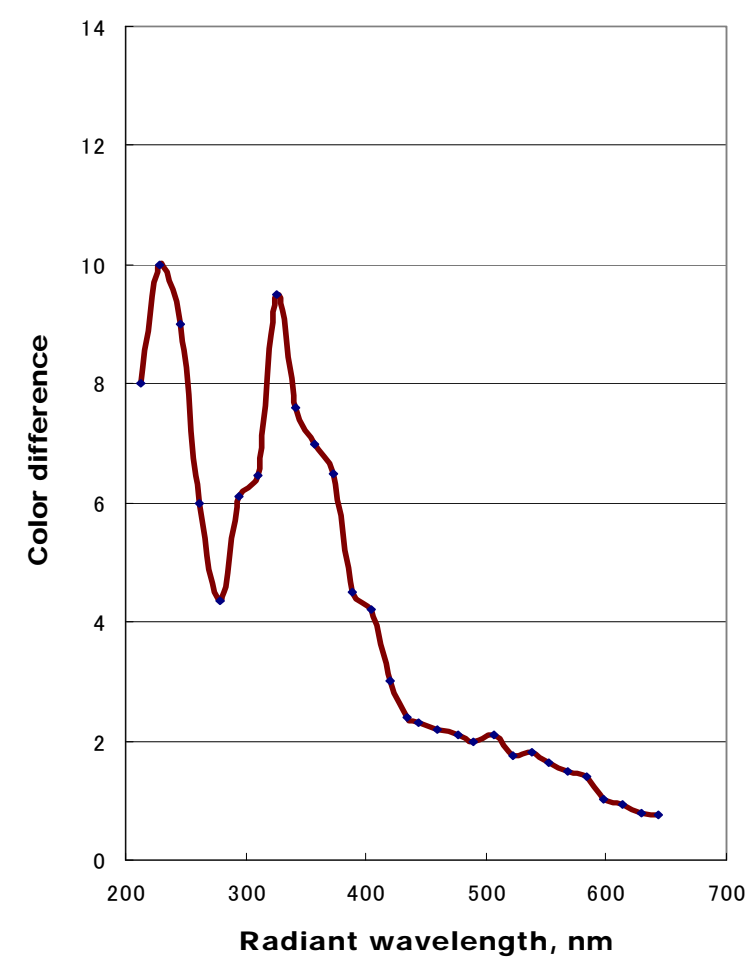

Figure 8. Wavelength sensitivity characteristics for the fading of Tame-Urushi under a radiant energy of $5 \mathrm{MJ} / \mathrm{m}^{2} / \mathrm{nm}$ at each wavelength.

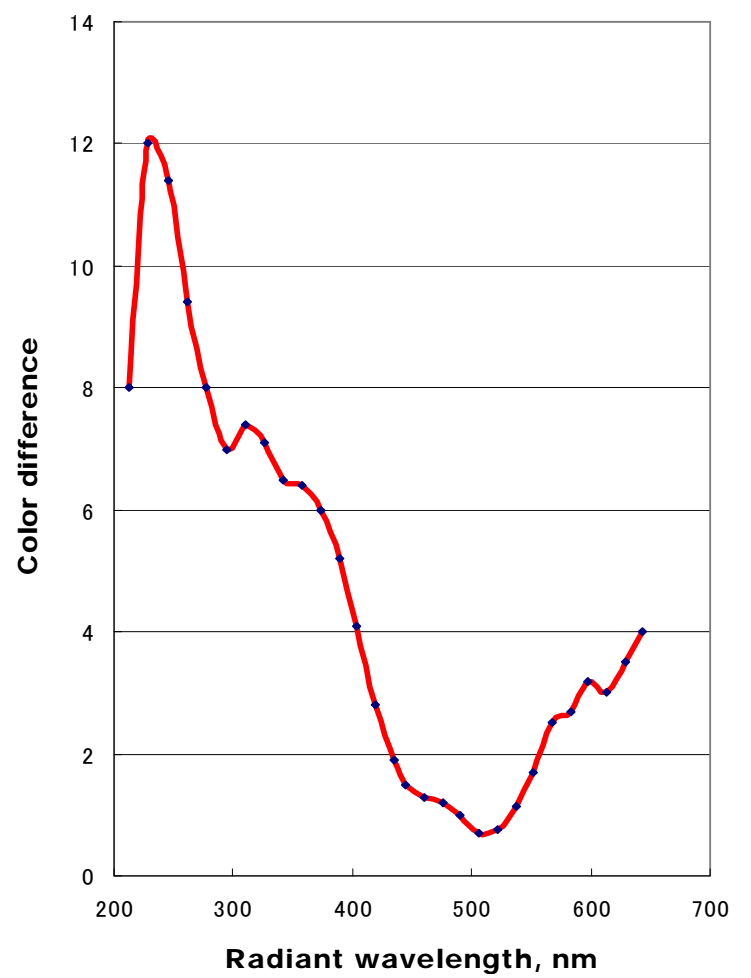

Figure 9. Wavelength sensitivity characteristics for the fading of Shuurushi under a radiant energy of $5 \mathrm{MJ} / \mathrm{m}^{2} / \mathrm{nm}$ at each wavelength. and a half years for black lacquer under the display lights in museums [3]. This is further supported by the result in Figure 9.

Figure 10 shows wavelength sensitivity characteristics for the degradation of Ao-Urushi under a radiant energy of $5 \mathrm{MJ} / \mathrm{m}^{2} / \mathrm{nm}$ at each wavelength. The peak is observed at $315 \mathrm{~nm}$ and a shoulder at around $250 \mathrm{~nm}$ in the UVB-UVC range. A broad shoulder peak also exists in the UVA range. Moreover, a peak at around $600 \mathrm{~nm}$ in the visible light range is observed as a result of degradation. However, the levels of color difference are lower compared to previous Tame-Urushi and Shu-Urushi specimens. Ao-Urushi is considered to degrade relatively faster compared to Tame-Urushi and Shu-Urushi specimens.

Figure 11 shows wavelength sensitivity characteristics for the degradation of Shin-Urushi under a radiant energy of $5 \mathrm{MJ} / \mathrm{m}^{2} / \mathrm{nm}$ at each wavelength. The levels of color difference are very low at all wavelengths compared to other lacquer specimens in this study. This implies that Shin-Urushi may be inert to visible light. However, a noticeable change is observed in the UV range. The degradation caused by UV irradiation can be recognized in Figure 11, although the level is very low. While ShinUrushi is resistant to visible light, UV light can still cause degradation of the polymer. This observation is

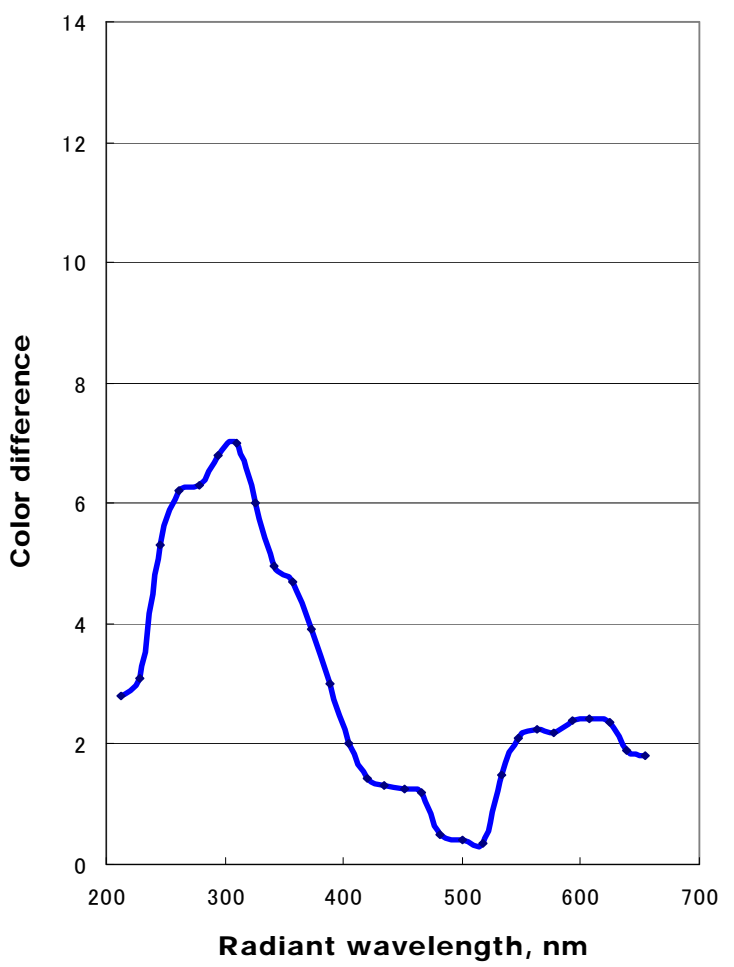

Figure 10. Wavelength sensitivity characteristics for the fading of Ao-Urushi under a radiant energy of $5 \mathrm{MJ} / \mathrm{m}^{2} / \mathrm{nm}$ at each wavelength. 


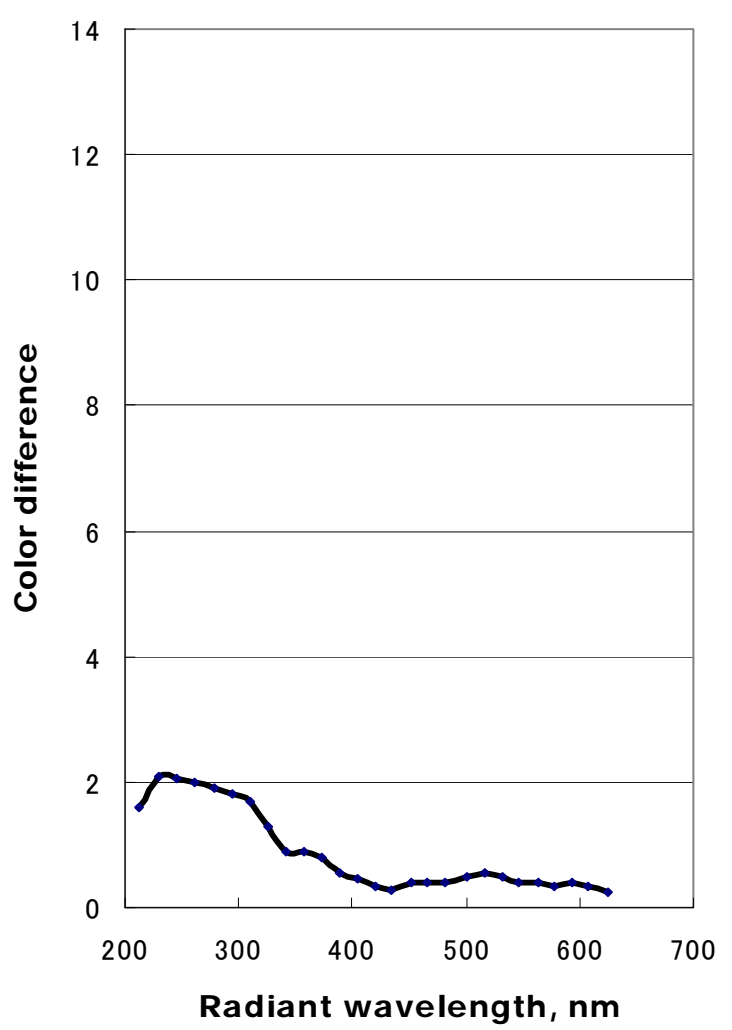

Figure 11. Wavelength sensitivity characteristics for the fading of Shin-Urushi under a radiant energy of $5 \mathrm{MJ} / \mathrm{m}^{2} / \mathrm{nm}$ at each wavelength.

consistent with warnings that lacquer should not be exposed to light below $400 \mathrm{~nm}$ [3]. This appears to be generally accepted and related to the relationship $E=h v$. However, our results indicate other aspects of the problem, as previously described. Visible light also has a considerable impact on the degradation of some lacquers.

The structure of lacquer crafts is complex, and a combination of many factors influences their degradation. Photoreactions are generally related to specific wavelengths, which are designated by the energy gap, as explained by quantum chemistry. In our study, pigmented lacquers had different wavelength sensitivity to degradation. Therefore, those pigments are expected to transfer their absorbed irradiation to characteristic energy gaps in the micro mechanism of the degradation process.

\section{Conclusions}

In this study, the degradation characteristics of pigmented Japanese lacquer were investigated by wavelength sensitivity analysis on the basis of radiant energy. Specimens were exposed to monochromatic light and the degradation characteristics were compiled as action spectra. We obtained the following results:

Tame-Urushi (brown) displayed peak degradation ma- xima at 220 and $315 \mathrm{~nm}$. A wide shoulder peak was also observed in UVA. As for Shu-Urushi (cinnabar), in addition to the peaks in UVA-UVB, a strong peak was observed in the visible light range. The results indicate that not only UVA and UVB but also visible light of wavelength $510-650 \mathrm{~nm}$ has a significant degradation effect for this lacquer. Ao-Urushi (green) showed similar characteristics, with lower degree of degradation. Shin-Urushi (black) was not seriously damaged by light although the UV exposure caused small degree of degradation.

This study provides experimental evidence that Japanese lacquer responds differently to light of various wavelengths and that specific wavelengths, including those in the visible range, can cause significant degradation. Further research is necessary to completely understand the nature of Japanese lacquer. However, this study provided insight into new aspects of the degradation characteristics of Japanese lacquer.

\section{REFERENCES}

[1] M. Webb, "Lacquer: Technology and Conservation," Butterworth-Heinemann, Oxford, 2000, p. 54.

[2] A. Burmester, "Far Eastern Lacquers: Classification by Pyrolysis Mass Spectrometry," Archaeometry, Vol. 25, No. 1, 1983, pp. 45-58. doi:10.1111/j.1475-4754.1983.tb00660.x

[3] N. Umey, "Oriental Lacquer," Conservation News, No. 32, 1987, pp. 23-25.

[4] M. Webb, "Methods and Materials for Filling Losses on Lacquer Objects," Journal of the American Institute for Conservation, Vol. 37, No. 1, 1998, pp. 117-133. doi: $10.2307 / 3179915$

[5] A. L. Andrady, A. Torikai and T. Kobatake, "Spectral Sensitivity of Chitosan Photodegradation," Journal of Applied Polymer Science, Vol. 62, No. 9, 1996, pp. 1465-1471. doi:10.1002/(SICI)1097-4628(19961128)62:9<1465::AID -APP16>3.0.CO;2-Y

[6] Z. F. Zhang, X. Z. Hu and Z. B. Luo, "Wavelength Sensitivity of Photooxidation of Polypropylene," Polymer Degradation and Stability, Vol. 51, No. 1, 1996, pp. 93-97. doi:10.1016/0141-3910(95)00210-3

[7] X. Z. Hu, "Wavelength Sensitivity of Photo-Oxida- tion of Polyethylene," Polymer Degradation and Stability, Vol. 55, No. 2, 1997, pp. 131-134. doi:10.1016/S0141-3910(96)00120-6

[8] Y. Fukuda and Z. Osawa, "Wavelength Effect on the Photo-Degradation of Polycarbonate and Poly(Methyl Methacrylate)-Confirmation of the Photo-Degradation Mechanism of PC/PMMA Blends," Polymer Degradation and Stability, Vol. 34, No. 1-3, 1991, pp. 75-84. doi:10.1016/0141-3910(91)90112-5

[9] A. L. Andrady, N. D. Searle and L. F. E. Crewdson, "Wavelength Sensitivity of Unstabilized and UV Stabilized Polycarbonate to Solar Simulated Radiation," Polymer Degradation and Stability, Vol. 35, No. 3, 1992, pp. 


\section{5-247. doi:10.1016/0141-3910(92)90031-Y}

[10] N. S. Allen and M. Edge, "Fundamentals of Polymer Degradation and Stabilization," Elsevier Applied Science, London and New York, 1992.

[11] A. L. Andrady, "Wavelength Sensitivity of Polymer Photodegradation," Advances in Polymer Sciences, Vol. 128, 1997, pp. 49-94.

[12] B. Forsthuber and G. Grüll, "The effects of HALS in the Prevention of Photo-Degradation of Acrylic Clear Topcoats and Wooden Surfaces," Polymer Degradation and Stability, Vol. 95, No. 5, 2010, pp. 746-755. doi:10.1016/j.polymdegradstab.2010.02.016

[13] H. Hintz, H.-J. Egelhaaf, H. Peisert and T. Chassé, "Photo-Oxidation and Ozonization of Poly(3-Hexylthiophene) Thin Films as Studied by UV/VIS and Photoelectron Spectroscopy," Polymer Degradation and Stability, Vol. 95, No. 5, 2010, pp. 818-825.

[14] Q. Shi, S. Zhong, Y. Chen and A. Whitaker, "PhotoCrosslinking Copolymers Based Polyanhydride and $1 \mathrm{G}$ Polyamidoamine-Methacrylamide as Bone Tissue Engineering: Synthesis, Characterization, and in Vitro Degradation," Polymer Degradation and Stability, Vol. 95, No. 10, 2010, pp. 1961-1968.

[15] F. Bezati, V. Massardier, J. Balcaen and D. Froelich, "A Study on the Dispersion, Preparation, Characterization and Photo-Degradation of Polypropylene Traced with Rare Earth Oxides," Polymer Degradation and Stability, Vol. 96, No. 1, 2011, pp. 51-59.

[16] T. Potta, C. J. Chun and S. C. Song, "Controlling the Degradation Rate of Thermoresponsive Photo-Cross-Linked Poly(Organophosphazene) Hydrogels with Compositions of Depsipeptide and PEG Chain Lengths," Polymer Degradation and Stability, Vol. 96, No. 7, 2011, pp. 12611270 .

[17] M. Watanabe, "The OKAZAKI Large Spectrograph and the Extension, to the Ultraviolet Region, of the Action Spectra for the Signaling Effects of Blue and Near-Ultraviolet Light in Plants and Fungi," Photomedicine and Photobiology, Vol. 10, 1988, pp. 83-94.

[18] W. I. Catherine and M. M. Terence, "UV-Action Spectrum $(254-405 \mathrm{~nm})$ for Inhibition of a $\mathrm{K}^{+}$-Stimulated Adenosine Triphosphatase from the Plasma Membrane of ROSA DAMASCENA," Photochemistry and Photobiology, Vol. 36, No. 5, 1982, pp. 537-542. doi:10.1111/j.1751-1097.1982.tb04413.x

[19] A. Curtis, P. Cole, F. Donald and E. D. Ronald, "An Action Spectrum for UV Photocarcinogenesis," Photochemistry and Photobiology, Vol. 43, No. 3, 1986, pp. 275-284. doi:10.1111/j.1751-1097.1986.tb05605.x

[20] M. J. Peak, J. G. Peak, M. P. Moehring and R. B. Webb, "Ultraviolet Action Spectra for DNA Dimmer Induction, Lethality, and Mutagenesis in Escherichia coli with Emphasis on the UVB Region," Photochemistry and Photobiology, Vol. 40, No. 5, 1984, pp. 613-620. doi:10.1111/j.1751-1097.1984.tb05349.x

[21] P. C. Crews, "A Comparison of Selected UV Filtering Material for the Reduction of Fading," Journal of the
American Institute for Conservation, Vol. 28, No. 2, 1989, pp. 117-125. doi:10.2307/3179484

[22] K. Himeno, Y. Okada and Z. Morita, "Photofading of Monoazo Disperse Dyes on Polyester and Polyamide Substrates," Dyes and Pigments, Vol. 45, No. 2, 2000, pp. 109-123. doi:10.1016/S0143-7208(00)00009-7

[23] K. Katsuda, T. Omura and T. Takagishi, "Photodegradation Behavior of Dyes in Solution," Dyes and Pigments, Vol. 36, No. 3, 1998, pp. 231-241. doi:10.1016/S0143-7208(97)00017-X

[24] N. Katsuda, T. Omura and T. Takagishi, "Photodegradation of an Anthraquinone Type Disperse Dye on Polyester, Diacetate, and Triacette Fibers and in Solution," Dyes and Pigments, Vol. 34, No. 2, 1997, pp. 147-157. doi:10.1016/S0143-7208(96)00066-6

[25] N. Katsuda, K. Otake, T. Omura and T. Takagishi, "Effect of Ultraviolet Absorbing Agents on Photodegradation Behavior of a Disperse Dye," Dyes and Pigments, Vol. 36, No. 3, 1998, pp. 193-204. doi:10.1016/S0143-7208(97)00003-X

[26] N. Katsuda, S. Yabushita, K. Otake, T. Omura and T. Takagishi, "Photodegradation of a Disperse Dye on Polyester Fiber and in Solution," Dyes and Pigments, Vol. 31, No. 4, 1996, pp. 291-300. doi:10.1016/0143-7208(96)00012-5

[27] M. Makansi, "Effect of Ageing on Dyeability of Nylon Yarns," American Dyestuff Reporter, Vol. 18, No. 1, 1993, pp. 27-35.

[28] U. Meyer, J. Wang, Y. Xia, J. Yang and H. Zollinger, "Dye-Fiber Bond Stabilities of Some Reactive Dyes on Silk," Journal of the Society of Dyers and Colourists, Vol. 102, No. 1, 1986, pp. 6-11.

[29] D. Rastogi, K. Sen and M. Gulrajani, "Photofading of Reactive Dyes on Silk and Cotton: Effect of Dye-Fiber Interactions," Coloration Technology, Vol. 117, No. 4, 2001, pp. 194-197. doi:10.1111/j.1478-4408.2001.tb00060.x

[30] T. Sato, N. Takada, M. Ueda, T. Nakamura and M. R. Luo, "Comparison of Instrumental Methods for Assessing Colour Fastness. Part 1: Change in Colour," Journal of the Society of Dyers and Colourists, Vol. 113, No. 1, 1997, pp. 17-24.

[31] Y. P. Wang and I. J. Wang, "Photolytic Behavior of Some Azo Pyridone Disperse Dyes on Polyester Substrates," Textile Research Journal, Vol. 62, No. 1, 1992, pp. 15-20.

[32] K. Yoshizumi and P. C. Crews, "Characteristics of Fading of Wool Cloth Dyed with Selected Natural Dyestuffs on the Basis of Solar Radiant Energy," Dyes and Pigments, Vol. 58, No. 3, 2003, pp. 197-204. doi:10.1016/S0143-7208(03)00065-2

[33] A. Imaizumi and K. Yoshizumi, "Effect of Substrates on Action Spectra of Fading of a Selected Disperse Dyestuff under Light Radiation," Textile Research Journal, Vol. 76, No. 10, 2006, pp. 757-764. doi:10.1177/0040517506070056

[34] A. Imaizumi and K. Yoshizumi, "Fading Characteristics of a Disperse Dye on Cellulose Triacetate, Polyester and 
Nylon Fabric Substrates under Monochromatic Light Radiation," Coloration Technology, Vol. 122, No. 2, 2006, pp. 86-92. doi:10.1111/j.1478-4408.2006.00014.x

[35] E. Takamura, K. Yoshizumi and P. C. Crews, "Photo Yellowing and Photo Bleaching of Silk and Wool Fabrics under Monochromatic and Multichromatic Light Radiation," The Textile Specialty Group Postprints, American
Institute for Conservation of Historic \& Artistic Works, Vol. 515, 2000, pp. 75-81.

[36] CIE (International Commission on Illumination), "A Reference Action Spectrum for Ultraviolet Induced Erythema in Human Skin," International Commission on Illumination Journal, Vol. 6, No. 1, 1987, pp. 17-22. 